\title{
Topical vitamin E and hydrocortisone acetate treatment after photorefractive keratectomy
}

\begin{abstract}
Purpose To investigate the effects of topical vitamin $\mathrm{E}$ and hydrocortisone acetate treatments on corneal healing response after $-10.0 \mathrm{D}$ photorefractive keratectomy (PRK) in rabbits.

Methods Thirty-three New Zealand white rabbits were divided into four groups and -10 D PRK was performed under in vivo conditions. Following PRK, group $1(n=9)$ received no topical treatment and served as control. Group $2(n=8)$ received $0.1 \%$ hydrocortisone acetate ointment twice a day, group $3(n=8)$ received $1 \%$ vitamin E ointment and group $4(n=8)$ received both $0.1 \%$ hydrocortisone acetate and $1 \%$ vitamin $E$ twice a day for a month. At the end of the third month, corneal haze was graded and the corneal hydroxyproline levels were measured, as a crude indicator of new collagen synthesis. Finally corneal samples were examined by transmission electron microscopy.

Results Non-homogeneously distributed strong haze was identified in group 1 which was greater than in the other groups; haze was least in groups 2 and 4 . Corneal hydroxyproline levels were found to be significantly lower in groups 2, 3 and 4 compared with the control (Student's $t$-test, $p<0.05)$. Histopathologically, the most aggressive wound healing response was detected in group 1 . The corneal wound healing response of group 2 was less than that of group 1 and equal to or more than that of group 4.

Conclusions Deep corneal photoablation induces an aggressive healing response, and topical hydrocortisone acetate reduces this corneal wound healing effectively. The inhibitory effect of topical vitamin $E$ on corneal wound healing seems to be less than that of hydrocortisone acetate, but combined treatment with these two drugs may have an additive effect in controlling corneal wound healing after PRK.
\end{abstract}

Key words Hydrocortisone acetate, Photorefractive keratectomy, Vitamin E
KAMIL BILGIHAN, SENGÜL OZDEK, CANDAN OZOǦUL, GÖKHAN GURELIK, AYSE BILGIHAN, BERATI HASANREISOĞLU
Corneal photoablation with $193 \mathrm{~nm}$ argon fluoride excimer laser is an effective technique for the treatment of refractive errors, removing corneal opacities and irregularities. ${ }^{1}$ Corneal haze and myopic regression are the major complications of the photorefractive keratectomy (PRK). These complications are associated with excessive corneal wound healing. PRK causes activation of the anterior stromal keratocytes resulting in proliferation as well as increased production of collagen and glycosaminoglycans. ${ }^{2}$

Excimer laser corneal tissue interaction may initiate free radical formation in the cornea. There are three possible sources of free oxygen radical production in the cornea during and after excimer laser photoablation: ultraviolet (UV) radiation (193 $\mathrm{nm}$ UV radiation, UV-C) that occurs during excimer laser treatment, ${ }^{3}$ excimer-laser-induced thermal increase in the corneal tissue during photoablation ${ }^{3,4}$ and accumulation of polymorphonuclear leucocytes on the laser-ablated surface. ${ }^{5}$ Free radicals are toxic products creating tissue damage, and may be responsible for some of the complications of the excimer laser corneal surgery. ${ }^{3}$

Therapies to inhibit these complications are under investigation. The clinical significance of steroid use after PRK is controversial. In rabbit studies the use of topical corticosteroids after PRK has a transient effect in reducing the corneal haze and new connective tissue synthesis. ${ }^{6}$ Alpha-tocopherol (vitamin E) is the major membrane-associated chain-breaking antioxidant in all tissues and is considered to be the first line of defence against oxygen radicals and lipid peroxidation. It has also been demonstrated that vitamin $\mathrm{E}$ is able to inhibit proliferation of human Tenon's capsule fibroblasts. $^{7}$

The purpose of this study was to investigate the effects of topical vitamin $\mathrm{E}$ and hydrocortisone acetate treatments on corneal healing response, after $-10.0 \mathrm{D}$ PRK in rabbits. With this aim, we graded the corneal haze by slit-lamp microscopic examination at the end of the third month, and measured the corneal hydroxyproline levels as crude indicator of new
K. Bilgihan

S. Ozdek

G. Gurelik

B. Hasanreisoğlu

Gazi University Medical

Faculty

Department of

Ophthalmology

Ankara, Turkey

C. Ozoğul

Gazi University Medical

Faculty

Department of Histology

Ankara, Turkey

A. Bilgihan

Gazi University Medical

Faculty

Department of Biochemistry

Ankara, Turkey

Kamil Bilgihan, MD

Defne Sitesi 3.Blok

53/10 Umitkoy 06530

Ankara, Turkey

Fax: +903122125794

e-mail:

bilgihan@behcet.tip.gazi.edu.tr.

Financial interest: None

Received: 15 March 1999 Accepted in revised form: 3 November 1999 
Table 1. Haze grading of the groups, 3 months after photoablation

\begin{tabular}{|c|c|c|c|c|c|c|c|c|c|c|}
\hline & \multicolumn{6}{|c|}{ Clinical haze (grade $0-4)^{a}$} & \multirow[b]{2}{*}{ No. of eyes } & \multirow[b]{2}{*}{ Haze (mean) } & \multirow[b]{2}{*}{$p$ value } & \multirow[b]{2}{*}{$t$ value } \\
\hline & 0 & 0.5 & 1 & 2 & 3 & 4 & & & & \\
\hline Group 1 (control) & - & - & - & 2 & 7 & - & 9 & 2.77 & & \\
\hline Group 2 (steroid) & - & 1 & 4 & 1 & 1 & - & 7 & 1.35 & $0.003^{b}$ & 4.80 \\
\hline Group 3 (vitamin E) & - & - & 1 & 4 & 2 & - & 7 & 2.14 & $0.03^{b}$ & 2.82 \\
\hline Group 4 (vitamin E + steroid) & - & 1 & 5 & 1 & - & - & 7 & 1.07 & $<0.0001^{b}$ & 9.13 \\
\hline
\end{tabular}

${ }^{a}$ Haze grading: 0 = cornea is clear; 0.5 = barely perceptible, between clear and trace; $1=$ trace, easily seen with slit-lamp microscope; $2=$ mild haze; 3 = moderate haze, iris details still visible; 4 = marked haze, iris details obscured.

${ }^{b}$ Compared with the control group (group 1).

collagen synthesis. Finally we examined the corneal samples by transmission electron microscopy.

\section{Materials and methods}

Thirty-three New Zealand white rabbits (average weight $3.2-4.1 \mathrm{~kg}$ ) were anaesthetised with an intramuscular injection of $25 \mathrm{mg} / \mathrm{kg}$ ketamine hydrochloride, $2.5 \mathrm{mg} / \mathrm{kg}$ xylazine and topical proparacaine hydrochloride. The central cornea was marked with a $7 \mathrm{~mm}$ trephine and the demarcated epithelium removed by a blunt spatula (Visitec, Sarasota, USA). We performed -10 D PRK with $193 \mathrm{~nm}$ excimer laser (Aesculap Meditec, Mel 60, Jena, Germany) under in vivo conditions. The fluence at the cornea was $250 \mathrm{MJ} / \mathrm{cm}^{2}$, with a repetition rate of $20 \mathrm{~Hz}$, and the diameter of the ablation zone was $6 \mathrm{~mm}$. Post-operative treatment included topical antibiotics and occlusion until epithelial resurfacing. Occlusion was achieved with a single 6/0 silk suture placed in the centre to fuse the lids. Epithelial resurfacing was completed by the end of the fourth postoperative day in all but two eyes. These two rabbits with delayed re-epithelialisation (one each from groups 2 and 4) were excluded from the study groups since they later developed corneal vascularisation.

Nine randomly chosen rabbits were included in group 1 and received no topical treatment after epithelial resurfacing and served as the control group (a topical drug-free ointment base could not be used because of technical problems). Remaining rabbits were also randomised to receive $0.1 \%$ hydrocortisone acetate ointment (Cortimycine, A.i Chevien, Istanbul) twice a day for 1 month (group 2, n=8), 1\% vitamin E ointment twice a day for 1 month (group 3, $n=8$ ) or both $0.1 \%$ hydrocortisone acetate and $1 \%$ vitamin $\mathrm{E}$ treatment (group $4, n=8$ ). One rabbit in group 3 died on the seventh post-operative day.

The composition of each sterile $100 \mathrm{~g}$ vitamin $\mathrm{E}$ ointment was: DL-alpha-tocopherol acetate $1.0 \mathrm{~g}$, Vaseline $88.8 \mathrm{~g}$, mineral oil $10.0 \mathrm{~g}$, methyl paraben $0.2 \mathrm{~g}$ (Bilim ilac,
Istanbul, Turkey). We did not use antioxidants (e.g. betacarotene) in the formulation as a preservative agent to protect vitamin $\mathrm{E}$ from oxygen, in order to see the antioxidant effects of only vitamin $E$ on the eye, without interference from other preservative antioxidant agents. The effective life of the product was 1 month, because the potency of vitamin E gradually decreases to $90 \%$ in 1 month with this formulation.

Corneal haze of the groups were graded under slitlamp microscopy at the end of the third month by an examiner masked to the treatment groups. We observed corneal vascularisation and scarring in 2 eyes (one from group 2 and the other from group 4) and these were excluded from the groups. Animals were then killed by an overdose of pentobarbital. The central corneal tissues were removed with a $6 \mathrm{~mm}$ trephine and hydrolysed in $6 \mathrm{~N}$ hydrochloric acid.

Corneal hydroxyproline was determined on the hydrolysate by a modification of the method of Bergman and Lexley. ${ }^{8}$ The corneal hydroxyproline levels of the vascular corneal samples were also measured. Student's $t$-test was used for the statistical analysis of the results. Two rabbits were chosen randomly from each group for histopathological evaluation and corneal samples were prepared for light and transmission electron microscopy.

Institutional guidelines regarding animal experimentation were followed and only one eye of each rabbit was used in the study.

\section{Results \\ Corneal haze}

The haze grading of the groups are shown in Table 1. Group 1 revealed non-homogeneously distributed strong haze (mean: 2.77$)$ which is statistically significantly greater than in all the other groups $(p<0.05)$ (Table 1$)$. Although there was no statistically significant difference between groups 2 and $4(t=1.54, p=0.17)$, group 4 revealed the lowest grades of haze (mean: 1.07).

Table 2. Corneal hydroxyproline levels of the groups ( $\mu \mathrm{g} / \mathrm{g}$ tissue)

\begin{tabular}{lccc}
\hline & Corneal hydroxyproline (mean \pm SD) & No. of eyes & $p$ value \\
\hline Group 1 (control) & $38.28 \pm 1.17$ & 9 & 7 \\
Group 2 (steroid) & $34.40 \pm 1.95$ & 7 & $<0.05^{a}$ \\
Group 3 (vitamin E) & $34.79 \pm 1.97$ & 7 & $<0.05^{a}$ \\
Group 4 (vitamin E + steroid) & $34.02 \pm 1.38$ & 2 & 3.98 \\
Corneal scarring, vascularisation & $39.02 \pm 0.42$ & 5.43 \\
\hline
\end{tabular}

${ }^{a}$ Compared with the control group (group 1). 


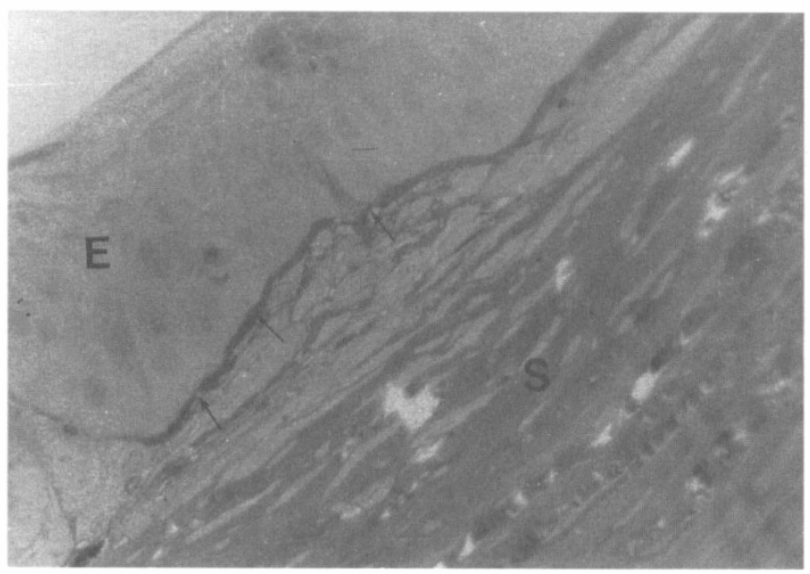

Fig. 1. Group 1. Epithelium (E), stroma (S), irregular basement membrane (arrows). Toluidine blue, $\times 400$.

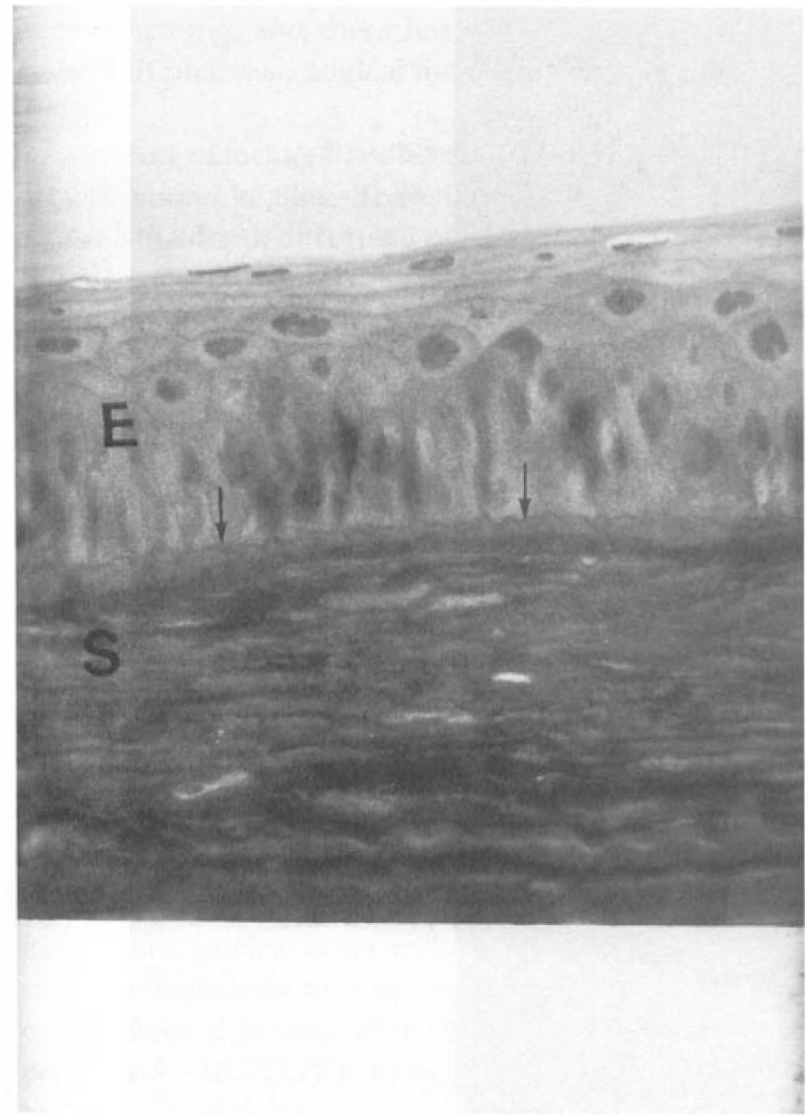

Fig. 2. Group 2. Epithelium (E), stroma (S), basement membrane (arrows). Toluidine blue, $\times 400$.

\section{Corneal hydroxyproline levels}

Corneal hydroxyproline levels are shown in Table 2.

Hydroxyproline levels in group 1 (mean: $38.28 \pm 1.17$ ) were significantly higher than in all the other groups (Student's $t$-test, $p<0.05)$. The corneal hydroxyproline levels of the two neovascular corneal samples (mean: $39.02 \pm 0.42$ ) were even higher than that in the control group.

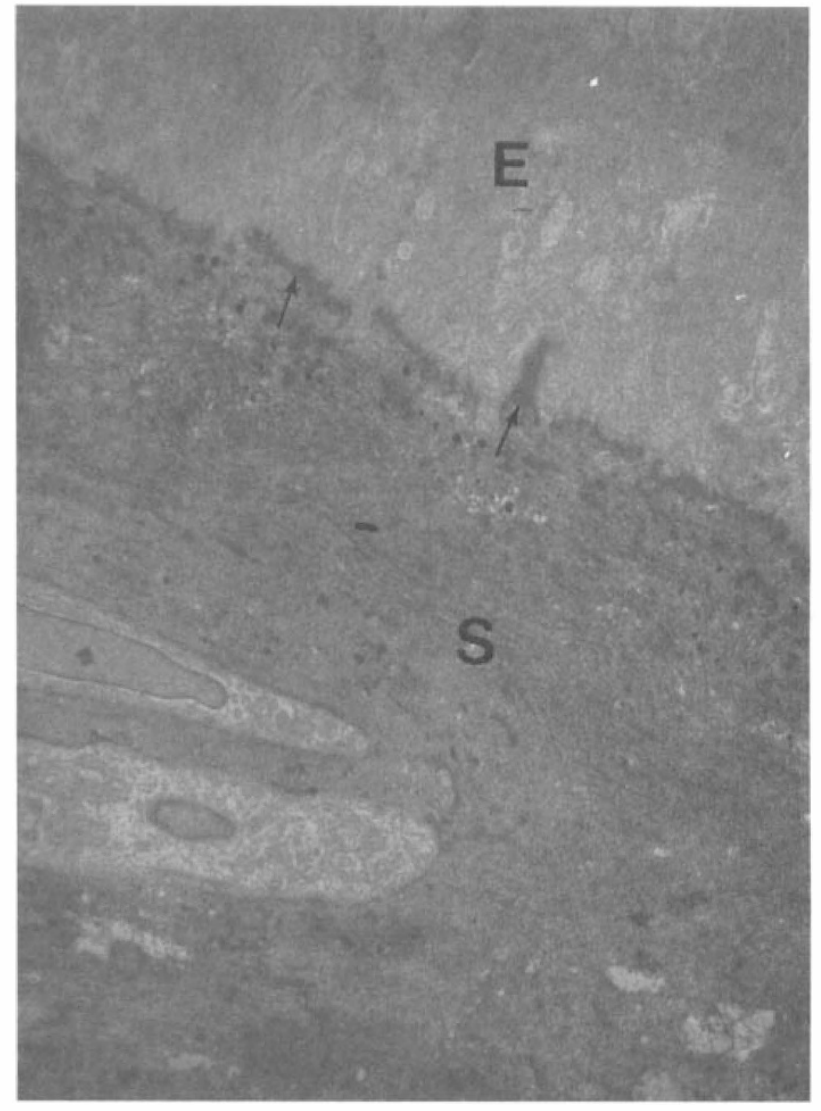

Fig. 3. Group 2. Epithelium (E), stroma (S), focal distributions in basement membrane (arrows). Osmium tetroxide, $\times 3000$.

\section{Microscopic examination}

Group 1 (control group)

There was epithelial hyperplasia with thickening up to ten layers. The newly formed basement membrane was irregular, and focal interruptions and undulations were detected. Increased keratocyte density with pleomorphism and vacuolisation were prominent in the anterior stroma. Most of the keratocytes $(74.4 \%)$ were located in the anterior half of the cornea in this group (Fig. 1). 


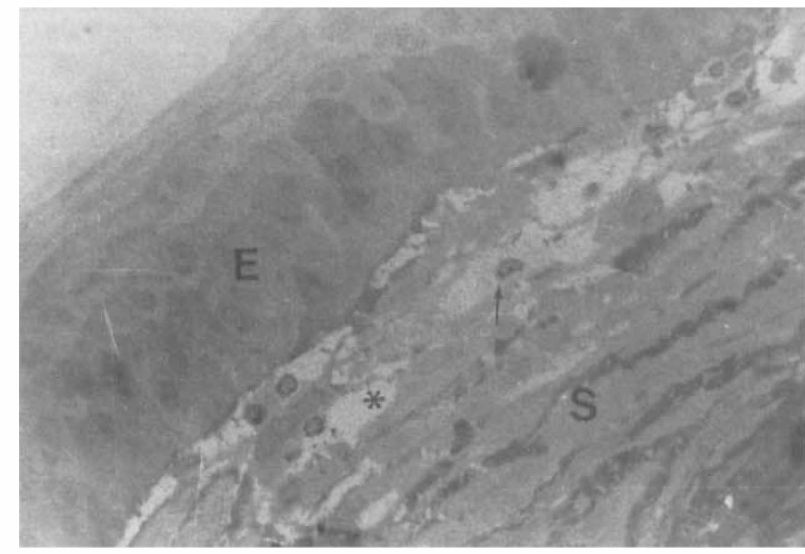

Fig. 4. Group 3. Epithelium (E), stroma (S), degenerated keratocytes (arrows), degenerative zones and vacuolisation in the stroma $\left({ }^{*}\right)$. Toluidine blue, $\times 400$.

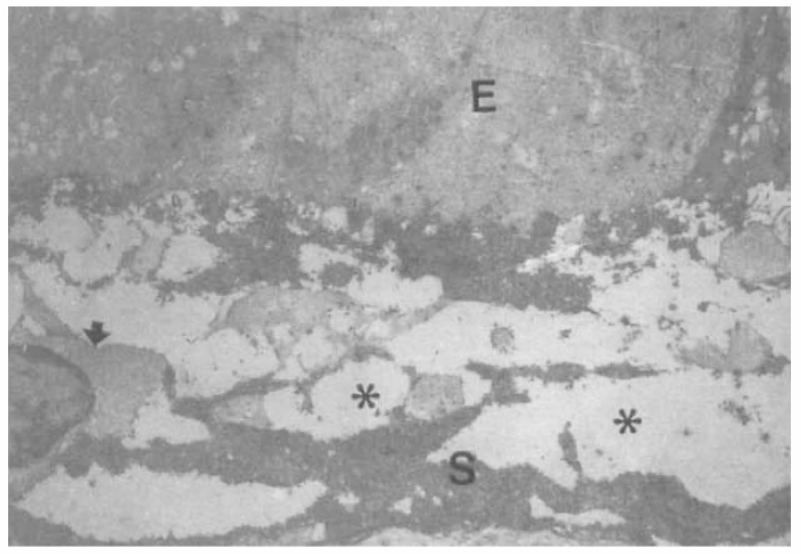

Fig. 5. Group 3. Epithelium (E), stroma (S), a large and degenerated keratocyte (arrow), vacuolisation in the stroma $\left.{ }^{*}\right)$. Osmium tetroxide, $\times 3000$

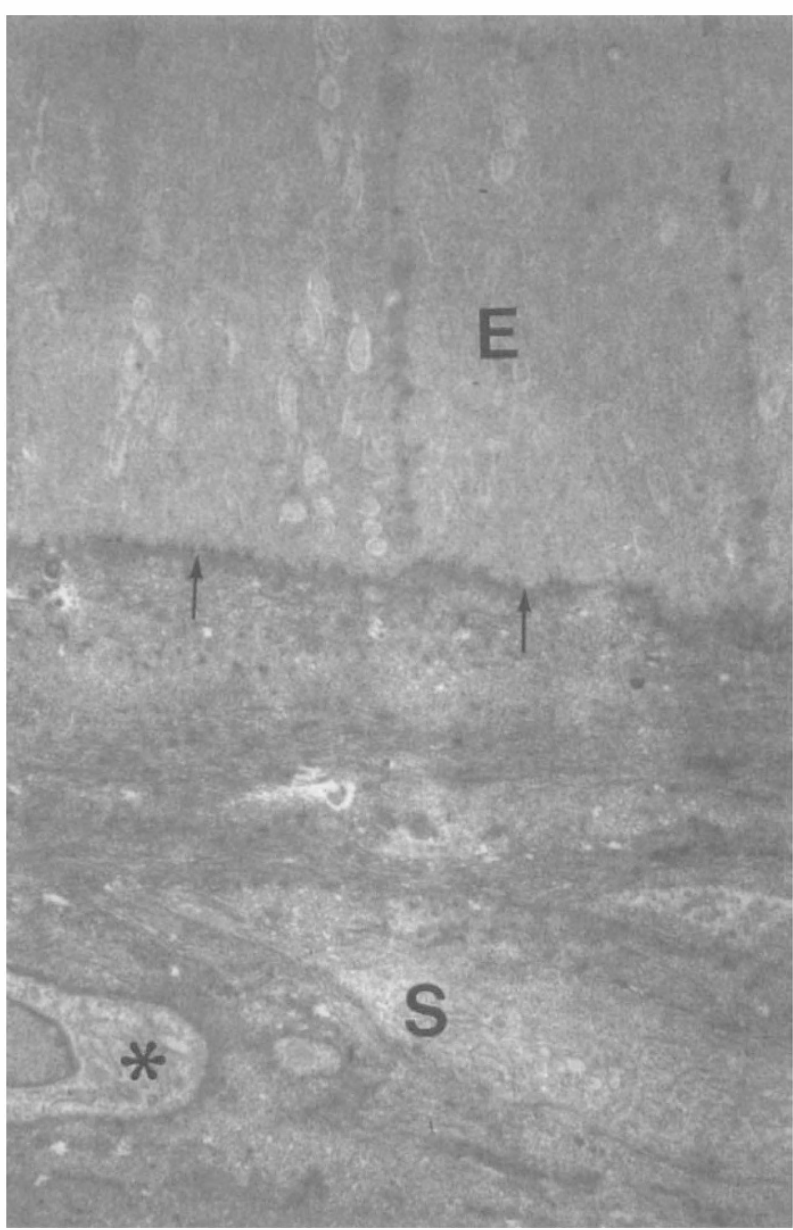

Fig. 6. Group 4. Epithelium (E), stroma (S), basement membrane (arrow), a keratocyte ${ }^{*}$ ). Osmium tetroxide, $\times 3000$.

\section{Group 2}

There was no significant alteration in the corneal structures. The epithelium was composed of six to eight layers. The anterior stroma was uniform and the keratocyte density was minimally increased, $55.8 \%$ of keratocytes being located in the anterior half of the stroma (Fig. 2). The basement membrane displayed focal disruptions with hemidesmosomes (Fig. 3).

\section{Group 3}

The epithelium was composed of eight to ten layers and the basement membrane was irregular. Degenerated keratocytes accumulated in the photoablated zone and $67.9 \%$ were located in the anterior half of the stroma (Fig. 4). The keratocytes had a polygonal shape and large nucleus. There were degenerative zones and vacuolisations in the stroma (Fig. 5). 


\section{Group 4}

No significant alterations were identified in group 4 . The epithelium was composed of six to eight layers. The basement membrane displayed a continuity with hemidesmosomes without any focal disruption (Fig. 6). The increase in the keratocyte density of the anterior stroma was minimal $(54.5 \%)$ in this group.

\section{Discussion}

PRK is considered to be a safe and effective procedure in low to moderate myopia. It does not seem to be so innocent, however, in the treatment of high myopia, because of the increased rates of haze and regression and decreased predictability of the attempted refractive results after deeper photoablations. ${ }^{9,10}$ These complications are the result of excessive corneal wound healing, and there has been considerable interest in pharmacological modification of the healing process. $^{2}$

A variety of factors have been shown to be effective on corneal wound healing. There is a positive correlation between the depth of corneal photoablation and aqueous TGF- $\beta 1$ concentration, corneal aldehyde dehydrogenase and glutathione $\mathrm{S}$-transferase activities and the dose of the excimer energy change. ${ }^{11,12}$ These findings support the notion that PRK treatment of high myopia induces a greater healing response in the cornea, by inducing the secretion of growth factors and changing the corneal enzyme activities.

We have previously reported that excimer laser photoablation may change the free radical balance of the aqueous humour and there was a positive correlation between the depth of corneal ablation and the thermal increase of the corneal endothelial surface. ${ }^{3}$ The presence of lipid peroxidation in the superficial corneal stroma in excimer laser treated corneas was demonstrated in a recent study. ${ }^{5}$ Reactive oxygen radicals cause tissue damage by reacting with lipid components of the cell membranes, nucleic acids and sulphur-containing enzymes, and these may be responsible for excessive corneal wound healing after $\mathrm{PRK}^{3,12}$ In our study we performed $-10.0 \mathrm{D}$ PRK to induce corneal wound healing.

Corneal haze is the loss of transparency due to reflection or scattering of the light. An aggressive wound healing response leads to this structural disturbance after the treatment of high myopes and there is a relationship between the amount of haze and the regression of refraction. ${ }^{2}$ Subepithelial haze begins to develop in 4-6 weeks and relatively stable refraction is achieved in 3-5 months. ${ }^{2,13}$ In rabbit models, the loss of corneal transparency is considered to be a consequence of increased keratocyte density, vacuoles containing glycosaminoglycans, or newly synthesised collagen fibres, which have large diameters and greater interfibre spacing than normal. ${ }^{14}$ Hydroxyproline is found mainly in collagens, where it accounts for about $13 \%$ of the total amino acid content and is derived from proline by post- translational hydroxylation. Because the hydroxyproline released during collagen degradation is not reused in collagen synthesis, it is used as a crude marker of collagen metabolism. ${ }^{15}$

Corticosteroids are demonstrated to inhibit stromal wound healing both by direct effects on stromal fibroblasts (decreased DNA synthesis) and by inhibiting collagen synthesis and subepithelial collagen deposition in animal experiments. ${ }^{16}$ Although the clinical significance of steroids after PRK is controversial, topical steroid therapy following PRK has been demonstrated to reduce subepithelial haze or regression. ${ }^{13}$ Some surgeons believe that the role of corticosteroids in PRK is very limited and there is no justification for their routine use after PRK. ${ }^{17}$ In a recent clinical study the effects of topical corticosteroids on refractive outcome and corneal haze after PRK were investigated and the authors found that corticosteroid therapy plays a beneficial role after PRK for high myopia when initiated soon after surgery. ${ }^{18}$ On the other hand, corticosteroid use is hazardous in that when given in large topical doses for long periods, up to $15-30 \%$ of patients may have increased intraocular pressure as well as increased risk of cataract formation. ${ }^{19,20}$

Vitamin E (alpha-tocopherol) is the major membraneassociated chain-breaking antioxidant in all tissues and is considered the first line of defence against lipid peroxidation and oxygen radicals. It has been demonstrated that vitamin $\mathrm{E}$ is able to inhibit proliferation of human Tenon's capsule fibroblasts. ${ }^{7}$ Vitamin E also inhibits growth and/or induces morphological differentiation in several cell types. ${ }^{21}$ The use of mitomycin $C$ and interferon-alpha $2 b$ were reported to reduce the corneal haze in rabbits. ${ }^{22,23}$

In this study we induced an aggressive stromal wound healing response and investigated the effects of topical hydrocortisone acetate and vitamin E treatments. We used the topical therapy for 1 month because the potency of vitamin E gradually decreases to $90 \%$ in 1 month with this formulation. We observed the animals for 3 months, as the subepithelial haze peaks at 8-12 weeks post-operatively.

We observed maximum haze in group 1 (control group), and the minimum haze in groups 2 and 4 (Table 1). Haze distribution between groups made us think that topical vitamin E treatment may have some inhibitory effect on corneal haze formation, but not so impressive as the effect of hydrocortisone acetate. Although the difference between the steroid-only group (group 2) and the steroid + vitamin E group (group 4) is not statistically significant, the combined treatment group had the lowest grades of haze, which suggests that vitamin $\mathrm{E}$ may have an additive effect on reducing corneal haze.

Corneal hydroxyproline levels were found to be significantly lower in groups 2, 3 and 4 compared with the control group (Student's t-test, $p<0.05$ ). These results suggest that topical treatment with hydrocortisone acetate and vitamin $\mathrm{E}$ inhibits new collagen synthesis in the cornea after deep photoablation. Measurement of 
hydroxyproline levels in corneal tissue is not thought to be a sensitive indicator of new collagen synthesis, but we found the highest levels of the corneal hydroxyproline in corneas with the most aggressive wound healing (corneal scar and vascularisation). Additionally, the results of the slit-lamp and microscopic examinations showed parallelism with the corneal hydroxyproline levels. Measurements of corneal hydroxyproline levels thus appear to provide some information about corneal collagen synthesis.

Microscopic examination of the corneal samples showed the regenerative response of the corneal tissue after deep PRK. The most aggressive wound healing response was detected in group 1. Epithelial hyperplasia, basement membrane irregularity, anterior stromal disorganisation and increased keratocyte density in the anterior half of the stroma $(74.4 \%)$ were prominent in group 1 . The wound healing response of group 2 was less than that of group 1 and equal to or greater than that of group 4 . These findings suggest that topical corticosteroid treatment inhibits stromal wound healing when initiated soon after PRK. The microscopic findings of group 3 showed minimal differences from the control group; the epithelial hyperplasia and the accumulation of keratocytes in the anterior stroma were less, but basement membrane irregularity and anterior stromal disorganisation were similar to group 1 . The histological investigation in group 4 showed almost regular stromal architecture, no focal disruption but minimal undulation in the basement membrane. These histological findings also suggest that topical vitamin $\mathrm{E}$ therapy itself may have little or no effect on corneal wound healing after PRK but may have an additive effect when it is combined with topical corticosteroid therapy. The keratocyte density of the anterior stroma was minimal $(54.5 \%)$ and the basement membrane was regular in group 4.

The effects of corticosteroid treatment on the corneal wound healing response after PRK have been investigated in many studies. This is the first study to investigate the effects of vitamin E after PRK. Vitamin $E$ is a potent antioxidant and is able to inhibit proliferation in several cell types (e.g. human Tenon's capsule fibroblasts). ${ }^{7}$ Our results suggest that topical corticosteroid treatment has a beneficial effect on reducing corneal haze and inhibiting stromal wound healing when initiated soon after PRK; that vitamin E treatment alone may have a limited effect on corneal wound healing after PRK; and that vitamin E treatment may have an additive effect when combined with topical corticosteroid therapy since the least corneal healing response (as indicated by the lowest levels of hydroxyproline, reduced corneal haze and undisturbed basement membrane) was observed with the combined treatment with these two agents in our study (Tables 1, 2).

In conclusion, deep corneal photoablation induces an aggressive healing response and topical hydrocortisone acetate treatment reduces corneal wound healing effectively. The effect of topical vitamin E treatment is less than that of corticosteroid treatment, but combined treatment with these two drugs may have an additive therapeutic effect on controlling corneal wound healing after PRK.

The authors wish to thank Drs Senol Pak and Erol Teberoglu for their great assistance.

\section{References}

1. Seiler T. Refractive corneal surgery with lasers. Curr Opin Ophthalmol 1996;7:47-51

2. Tuft SJ, Rawe I, Meek K. Photorefractive keratectomy: implications for corneal wound healing with lasers. Br J Ophthalmol 1993;77:243-7.

3. Bilgihan K, Bilgihan A, Akata F, Türközkan N, Hasanreisoğlu B. Excimer laser corneal surgery and free oxygen radicals. Jpn J Ophthalmol 1996;40:154-7.

4. Niizuma T, Ito S, Hayashi M, Futemma M, Utsumi T, Ohashi $\mathrm{K}$. Cooling the cornea to prevent side effects of photorefractive keratectomy. J Refract Corneal Surg 1994;10:262-6.

5. Hayashi S, Ishimoto S, Wu G, Wee W, Rao N, McDonnell P. Oxygen free radical damage in the cornea after excimer laser therapy. Br J Ophthalmol 1997;81:141-4.

6. Nishida T, Tanaka T. Extracellular matrix and growth factors in corneal wound healing. Curr Opin Ophthalmol 1996;7:2-11.

7. Haas AL, Bobscoboinik D, Mojon DS, Bohnke M, Azzi A. Vitamin E inhibits proliferation of human Tenon's capsule fibroblasts in vitro. Ophthalmic Res 1996;28:171-5.

8. Bergman I, Lexley R. The determination of hydroxyproline in urine hydrolysates. Clin Chim Acta 1970;27:347-9.

9. Seiler T, Holschbach A, Derse M, Jean B, Genth U. Complications of myopic photorefractive keratectomy with the excimer laser. Ophthalmology 1994;101:153-60.

10. Ditzen K, Anschutz T, Schroder T. Photorefractive keratectomy to treat low, medium, and high myopia: a multicenter study. J Cataract Refract Surg 1994;20(Suppl):234-8.

11. Bilgihan K, Gürelik G, Okur H, Bilgihan A, Hasanreisoğlu B, Imir $T$. Aqueous transforming growth factor $\beta-1$ levels in rabbit eyes after excimer laser photoablation. Ophthalmologica 1997;211:380-3.

12. Bilgihan K, Bilgihan A, Hasanreisoğlu B, Türközkan N. Corneal aldehyde dehydrogenase and glutathione $\mathrm{S}$ transferase activity after excimer laser keratectomy in guinea pigs. Br J Ophthalmol 1998;82:300-2.

13. Garty DS, Kerr Muir MG, Lohmann CP, Marshall J. The effect of topical corticosteroids on refractive outcome and corneal haze after photorefractive keratectomy. Arch Ophthalmol 1992;110:944-52.

14. Rawe IM, Zabel RW, Tuft SJ, Chen V, Meek KM. A morphological study of rabbit corneas after laser keratectomy. Eye 1992;6:637-42.

15. Endres DB, Rude RK. Mineral and bone metabolism. In: Burtis CA, Ashwood ER, editors. Tietz textbook of clinical chemistry. 2nd ed. Philadelphia: Saunders, 1994:1941.

16. Tuft SJ, Zabel RW, Marshall J. Corneal repair following keratectomy: a comparison between conventional surgery and laser photoablation. Invest Ophthalmol Vis Sci 1989;30:1769-77.

17. Melanie CC, O'Brart DPS, Marshall J. Do topical corticosteroids have a role following excimer laser photorefractive keratectomy? J Refract Surg 1995;11:380-7.

18. Baek SH, Chang JH, Choi SY, Kim WJ, Lee JH. The effect of topical corticosteroids on refractive outcome and corneal haze after photorefractive keratectomy. J Refract Surg 1997;13:644-52. 
19. Kim JH, Sah WJ, Hahn TW, Lee YC. Some problems after photorefractive keratectomy. J Refract Surg 1994;10:226-30.

20. Bilgihan K, Gürelik G, Akata F, Hasanreisoğlu B.

Fluorometholone induced cataract after photorefractive keratectomy. Ophthalmologica 1997;211:394-6.

21. Azzi A, Boscoboinik D, Chatelain E, Ozer NK, Stauble B. d- $\alpha-$ Tocopherol control of cell proliferation. Mol Aspects Med 1993;14:265-71.
22. Amm M, Wetzel W, Winter M, Uthoff D, Duncker GIW. Histopathological comparison of photorefractive keratectomy and laser in situ keratomileusis in rabbits. J Refract Surg 1996;12:758-66.

23. Morlet N, Gillies MC, Crouch R, Maloof A. Effect of topical interferon-alpha $2 \beta$ on corneal haze after excimer laser photorefractive keratectomy in rabbits. Refract Corneal Surg 1993;9:443-51. 